\title{
Factors Affecting Quality of Nursing Education in Nursing Technical Institutes at Assuit Governorate
}

\author{
Shereen Mohamed Sobhy, Samah Mohamed Abdullah \& Hala Ramzy Youssef \\ Nursing Specialist in Nursing School at El-Minia city, Egypt. \\ Professor of Nursing Administration, Faculty of Nursing ,Assuit University, Egypt. \\ Professor of Nursing Administration, Faculty of Nursing ,Assuit University, Egypt.
}

\begin{abstract}
Nursing education programs are challenged to implement new innovative strategies to meet the workforce needs for the future. Aim of this study: determine the factors affecting quality of nursing education as perceived by nursing students and teachers in nursing technical institutes at Assuit City. Subjects \& Method: the present study was descriptive design conducted in two nursing institute(University nursing institute and Ministry of health institute at Assuit city)it consists of all second academic year nursing students in two technical nursing institute as following:(University nursing institute $(\mathrm{n}=150)$, Ministry of health institute $(\mathrm{n}=175)$ and all teachers who are teaching second year in the previous settings $(\mathrm{n}=20)$. Tool of study consist of two parts which included: personal data and self-administrated questionnaire tool used to determine the factors affecting quality of nursing education. Results: The incidental teaching is the most factor was not available followed by, clinical infrastructure, and physical facilities as studied subjects reported Conclusion: The incidental teaching is the most factor affecting quality of nursing education was not available. Recommendations: Asking the authorities body who responsible for the development of institutes to pay attention to the infrastructure and supply the institutes with the new buildings. Increase number of clinical teachers in clinical setting to facilitate students learning .
\end{abstract}

\section{Keywords: Nursing Education \& Factors Affect on Academic Performance.}

\section{Introduction}

The quality of nursing education is one of the key elements of quality healthcare services. The health staff needs to grow, develop and be better distributed across settings of care to continue to meet the increasing and changing needs in community for access to high-quality healthcare services. Also, highquality education and training in health service settings are necessary to prepare students to enter the health workforce, enabling them to gain essential experience in the theory and practice of delivering quality services in advance of assuming direct responsibility for patient care (Willis commission on nursing education report, 2012).

Nursing education is a term used to describe the overall body of knowledge that applies to nursing profession. It encompasses a variety of knowledge, skills, concepts, and practices which revolve around the unique concepts of nursing, health, the person and the environment (Melone, 2010). Increased complexity in today's nursing care playing a challenge to the theoretical and clinical training of nursing students, it was realized that theoretical studies are of great importance in nursing education and practice. This then led to reduction of the proportion of time spent on clinical experience while the time and courses in relation to theoretical studies was increased clinical training should be aligned to meet the challenges facing nursing practice. Although clinical training is still an essential part of student nurses' education, its role and application have changed in recent years. However, in nursing education, the classroom and clinical environment are linked and students must apply in clinical practice what they have learned in the classroom, online and through other exposures. (Harrison, 2010).

The challenge of education today is to offer school experiences that provide students with opportunities to develop the understandings, skills, and attitudes necessary to become lifelong learners, capable of identifying and solving problems and dealing with change. Moreover, students need to be able to communicate clearly, competently, and confidently from a broad knowledge base in order to make thoughtful and responsible decisions. Achieving these educational goals will provide students with the means to make connections between what they learn and how they live (Benner, 2010).

There are several factors affecting quality of nursing education including: potentiality of student, change in curriculum, qualified and experienced teacher, teaching methods, physical facilities, clinical infrastructure, constructive supervision, incidental teaching, nurse patient ratio and teacher student ratio, new technology, evaluation system, institutional polices, guidance and counseling, and opportunity of self-development (NLN, Transforming Clinical Nursing Education Report, 2009) 


\section{Significance of the Study}

Technical Nursing graduates are considered one of the main categories of nurses in providing patients care at health care setting, therefore special consideration should be given to this level of education to improve quality of patients care. (Farag, 2008)

So the investigator felt that it is necessary to conduct this study to determine the factors affecting quality of education at Technical Nursing Institutes.

\section{Aim of the study}

To determine the factors affecting quality of nursing education as perceived by nursing students and teachers in Nursing Technical Institutes at Assuit City.

\section{Research Questions}

- What are the factors affecting quality of nursing education as perceived by the teachers and nursing students in nursing technical institutes?

- Is there a significance difference between perspectives of nursing students and the teachers regarding the factors affecting quality of nursing education?

\section{Methods \\ Study design}

The descriptive research design was used in this study.

\section{Setting}

The present study was carried out in two Technical Nursing Institutes: University nursing institute and Ministry of health nursing institute at Assuit city.

\section{Subjects}

The study subjects consists of all second academic year nursing students in two technical nursing institute as following: (University nursing institute $(n=150)$ and Ministry of health institute $(n=175)$ at Assuit city, as well as all teachers who are teaching second years in the previous settings $(n=20)$.

\section{Data collection tool}

The study tool consisted of two parts, which included Part one Personal characteristics data sheet:

It was designed to collect data about studied nursing students and teachers in the same setting included: for students: (name, age, sex, setting) ,for teachers: (name, age, sex, years of experience and level of education).

Part two Factors affecting quality of nursing education questionnaire

A self-administrated questionnaire tool used to determine the factors affecting quality of nursing education adopted by (Bhushan, 2013) It consists of 101 items classified into 14 main items: potentiality of student ,change in curriculum, qualified and experienced teacher, teaching methods, physical facilities, clinical infrastructure, constructive supervision, incidental teaching, nurse patient ratio and teacher student ratio, new technology, evaluation system, institutional polices guidance and counseling and opportunity of self-development .

\section{Scoring System}

The study subject responses measured by using three points Likert scale ranging from (3) available and very essential, (2) for available and not essential, and (1) for not available.

\section{Pilot study}

A pilot study was carried out to assess clarity and applicability of the tool as well to identify the problems that may be encountered during the actual data collection. It was applied on $10 \%$ (Twenty six nursing students and six teachers from the health Technical Institute in both setting) which was excluded from the study subjects . The nursing students for pilot study were selected randomly from students name list by choose the first thirteen students names in both setting as well as selected six teachers randomly who presented in that day..Data collected from the pilot study was analyzed, their reliability was assessed in a pilot study by measuring their internal consistency using Cronbach's alpha coefficient method.

\section{Filed work}

The questionnaires were distributed to the study subjects after thoroughly explaining the purpose of the study and ask for participation. After obtaining verbal consent, the study tool was handled to participating students and teachers to be filled. Furthermore, request for cooperation and assurance that all information gathered was be treated strictly with confidentiality.

\section{Ethical Considerations}

The study was conducted with careful attention to ethical standards of research and rights of the participants . Oral agreement was taken from all study subjects in the present study. Research proposal was approved from ethical committee in the faculty of Nursing at Assiut University. The study was followed common ethical principles in research. The anonymity and confidentiality of response, voluntary participation and right to refuse to participate in the study was emphasized to the subject assured through coding the data .

\section{Statistical analysis}

The obtained data was reviewed, prepared for computer entry analyzed and tabulated. Descriptive statistics (frequencies and percentages, mean, and standard deviation) were done by using computer program SPSS version 19. T- test used to compare differences in the distribution of frequencies between different groups. It considered significant when Pvalues were less than $0.05 .(p \leq .05)$ 


\section{Results}

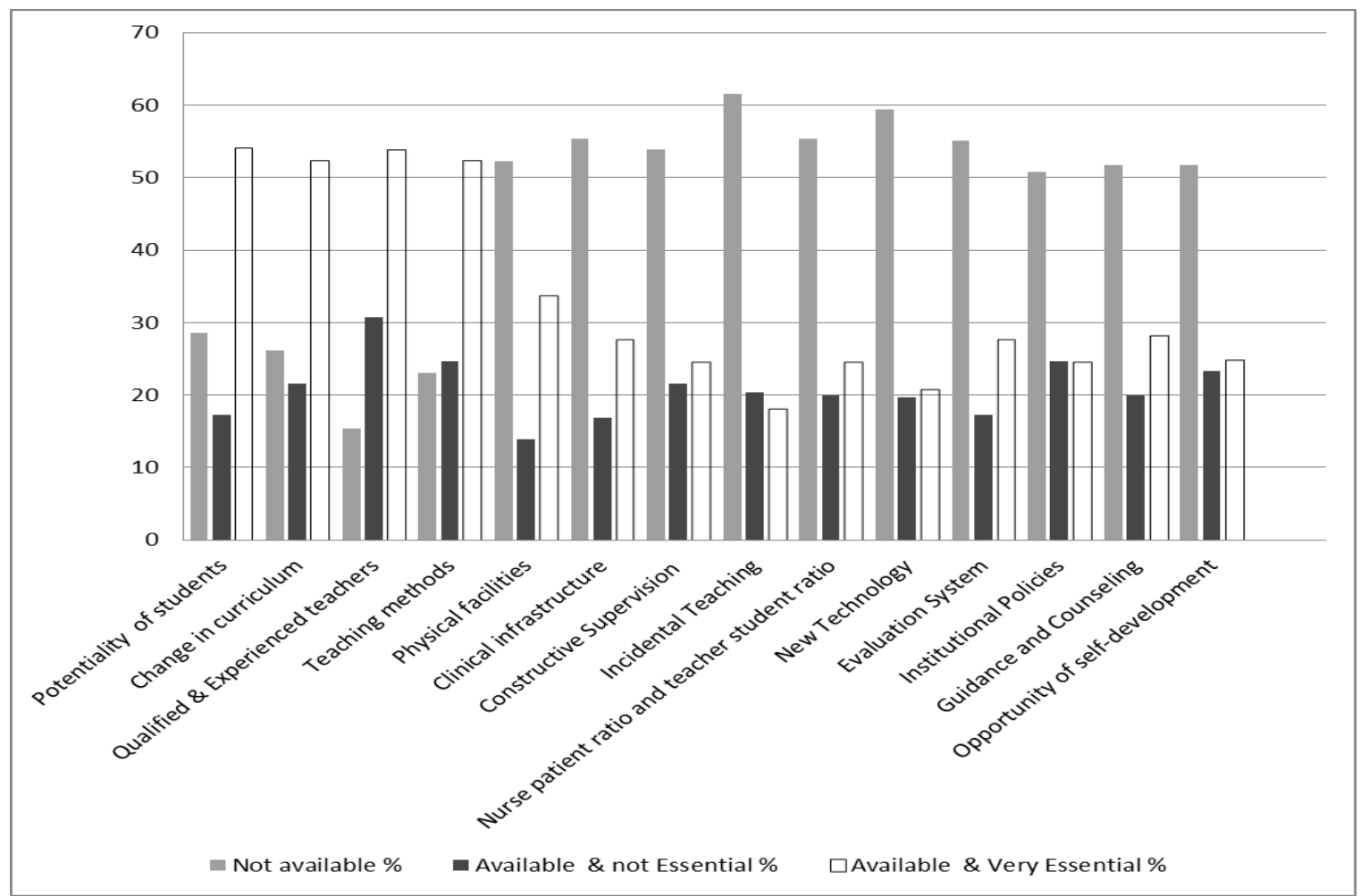

Figure (1): Frequency distribution of studied subjects responses related to all factors affecting quality of nursing education: $(n=345)$.

Table (1): Mean scores of response of University students and Ministry of health students regards all Factors affecting quality of nursing education $(n=325)$.

\begin{tabular}{|l|c|c|c|}
\hline \multicolumn{1}{|c|}{$\begin{array}{c}\text { Factors affecting quality of nursing } \\
\text { education }\end{array}$} & $\begin{array}{c}\text { University } \\
\text { students(n=150) }\end{array}$ & $\begin{array}{c}\text { Ministry of health } \\
\text { students(n=175) }\end{array}$ & P. value \\
\hline 1.Potentiality of students & $6.3 \pm 1.9$ & $4.6 \pm 1.4$ & $0.001^{* *}$ \\
\hline 2.Change in curriculum & $14.2 \pm 4.3$ & $13.1 \pm 4$ & $0.017^{*}$ \\
\hline 3.Qualified \& Experienced teachers & $17.5 \pm 5.3$ & $15.8 \pm 4.8$ & $0.003^{* *}$ \\
\hline 4.Teaching methods & $10.1 \pm 3.1$ & $6.4 \pm 2$ & $0.001^{* *}$ \\
\hline 5.Physical facilities & $8.8 \pm 2.7$ & $7.8 \pm 2.4$ & $0.004^{* *}$ \\
\hline 6.Clinical infrastructure & $3.2 \pm 1$ & $3.2 \pm 1$ & 1.000 \\
\hline 7.Constructive Supervision & $6.3 \pm 1.9$ & $5.1 \pm 1.6$ & $0.001^{* *}$ \\
\hline 8.Incidental Teaching & $3.2 \pm 1$ & $4.1 \pm 1.3$ & $0.005^{* *}$ \\
\hline 9.Nurse patient ratio and teacher student ratio & $9.2 \pm 2.8$ & $6.4 \pm 2$ & $0.001^{* *}$ \\
\hline 10.New Technology & $5.2 \pm 1.6$ & $3.1 \pm 0.9$ & $0.001^{* *}$ \\
\hline 11.Evaluation System & $4.7 \pm 1.4$ & $3.4 \pm 1$ & $0.001^{* *}$ \\
\hline 12. Institutional Policies & $6.1 \pm 1.9$ & $5.4 \pm 1.6$ & $0.003^{* *}$ \\
\hline 13.Guidance and Counseling & $6.5 \pm 2$ & $4.8 \pm 1.5$ & $0.001^{* *}$ \\
\hline 14.Opportunity of self-development & $5.2 \pm 1.6$ & $4.1 \pm 1.3$ & $0.001^{* *}$ \\
\hline Level of significance $=P<0.05$ & \multicolumn{2}{|c|}{ NOTE: indicates significance difference at P<0.05 }
\end{tabular}


Table (2): Comparison between students and teachers as regards to factors affecting quality of nursing education $(n=345)$.

\begin{tabular}{|l|c|c|c|}
\hline \multicolumn{1}{|c|}{$\begin{array}{c}\text { Factors affecting quality of nursing } \\
\text { education }\end{array}$} & $\begin{array}{c}\text { Students }(\mathbf{n}=\mathbf{3 2 5}) \\
\text { Mean+ SD }\end{array}$ & $\begin{array}{c}\text { Teachers }(\mathbf{n}=\mathbf{2 0}) \\
\text { Mean+ SD }\end{array}$ & P. value \\
\hline 1.Potentiality of students & $5.4 \pm 2.2$ & $5.8 \pm 1.9$ & 0.427 \\
\hline 2.Change in curriculum & $13.6 \pm 4.5$ & $12.5 \pm 3.7$ & 0.285 \\
\hline 3.Qualified \& Experienced teachers & $16.6 \pm 4.9$ & $16.2 \pm 5.2$ & 0.724 \\
\hline 4.Teaching methods & $8.1 \pm 2.3$ & $8.4 \pm 3.1$ & 0.580 \\
\hline 5.Physical facilities & $8.3 \pm 2.9$ & $8.6 \pm 4.1$ & 0.662 \\
\hline 6.Clinical infrastructure & $3.2 \pm 1.1$ & $2.6 \pm 1.8$ & $0.024^{*}$ \\
\hline 7.Constructive Supervision & $5.7 \pm 2.1$ & $5.5 \pm 2.4$ & 0.682 \\
\hline 8.Incidental Teaching & $3.7 \pm 1.3$ & $4.2 \pm 1.1$ & 0.093 \\
\hline 9.Nurse patient ratio and teacher student ratio & $7.7 \pm 2.6$ & $6.0 \pm 2.3$ & $0.004^{* *}$ \\
\hline 10.New Technology & $4.1 \pm 1.4$ & $3.0 \pm 1.7$ & $0.001^{* *}$ \\
\hline 11.Evaluation System & $4.0 \pm 1.9$ & $4.5 \pm 2.2$ & 0.258 \\
\hline 12.Institutional Policies & $5.7 \pm 2.7$ & $8.1 \pm 3.1$ & $0.001^{* *}$ \\
\hline 13.Guidance and Counseling & $5.6 \pm 2.1$ & $6.7 \pm 4.2$ & $0.036^{*}$ \\
\hline 14.Opportunity of self-development & $4.6 \pm 1.7$ & $5.4 \pm 2.3$ & $0.046^{*}$ \\
\hline
\end{tabular}

Level of significance $=P<0.05$

Figure (1): The results of this study revealed that the studied subjects rated incidental teaching as the most factor not available $(61.54 \%)$, followed by new technology $(59.38 \%)$, nurse patient ratio and teacher student ratio (55.38\%), evaluation system $(55.08 \%)$, clinical infrastructure (55\%), constructive supervision $(53.85 \%)$, physical facilities $(52 \%)$, guidance and counseling $(51.69 \%)$, opportunity of self-development (51.69\%), and institutional Policies as the last most factors not available (50.77\%). As well as the students in the studied subjects rated the potentiality of students as the most factor available and very essential $(54.15 \%)$ followed by, change in curriculum $(52.31 \%)$,qualified \& experienced teachers $(53.85 \%)$, and teaching methods as the last most factors available and very essential (52.31\%), with statistically significant difference between the University nursing students \& Ministry of health students for the all main factors affecting quality of nursing education except the clinical infrastructure was no statistical significant differences between them.

Table (1): Indicated that there was a highly statistical significant differences between the University nursing students \& Ministry of health nursing students for the all main factors affecting quality of nursing education except the clinical infrastructure was no statistical significant differences between them. Same score in both setting (3.2 \pm 1$)$. Also the table showed that the highest mean score regarding to all factors affecting quality of nursing education were in favor of the University nursing students except the incidental teaching were in favor of Ministry of health nursing students.
NOTE: indicates significance difference at $P<0.05$.

Table (2): Clarified that there was highly statistical significant differences between the students and the teachers. The highest mean score in favor of the students regarding to the clinical infrastructure, nurse patient ratio and teacher student ratio, and new technology. While the highest mean score in favor of the teachers regarding to institutional Policies, guidance and counseling, and opportunity of selfdevelopment. $(\mathrm{P}=<0.05)$.

\section{Discussion}

The quality education of nursing professional has been in constant revision since the end of the last century, relating welfare quality problems with training problems that led to demands for change in the education of these professionals (Graham, Richardson 2008) The findings of study showed that, was a highly statistical significant differences between the University nursing students \& Ministry of health nursing students for the all main factors affecting quality of nursing education except the clinical infrastructure was no statistical significant differences between them. Same score in both setting. This supported the report from (Sumari 2006 \& Bray et al., 2011) studies which indicated that the school skill laboratory and the hospital wards lacked equipment and other necessary supplies, which do not help students to practice and concretize what they learnt in the classroom. Also Searle, (2000) identified lack of equipment/infrastructure as one of the constraining factors affecting clinical training of students in nursing profession.

The findings revealed significant statistical differences regarding to all factors affecting quality 
of nursing education were in favor of the University nursing students except the incidental teaching were in favor of Ministry of health nursing students.

This finding might be due to lack of structure and the process for providing and gaining peer-review which need to be clearly identified and the purpose must be known to helps students learn or recall what successful practice looks like.

This findings was in line with Wanda, (2010) who are reported that there are benefits to developing competency in the process of peer-review in addition to providing an avenue for nursing students to practice critical appraisal skills and objective evaluation in the classroom setting. Specific guidelines, criteria, and rubrics help to organize the process of peer-review methods and help peers to develop their critical thinking skills

There is highly statistically difference between the students and the teachers. The highest mean percent in favor of the students regarding to the clinical infrastructure, nurse patient ratio and teacher student ratio, and new technology. While the highest mean percent in favor of the teachers regarding to institutional Policies, guidance and counseling, and opportunity of self-development.

This finding might be due to large number of the students and limited building and resources in technical institute. as well as rapid increases in enrolments, poor maintenance and aging capital stocks, rural to urban migration, and inefficient government planning and school construction .

These findings are in agreement with a study conducted by Starck, (2005) which showed that majority of the studied samples reported that there are significant infrastructure limitations related to the number of currently enrolled students is at or exceeds current institutional capacity. In order to accept more students, qualified faculty must be recruited and retained, infrastructure expanded and additional preceptors utilized.

In relation to institutional policies as a factor that affecting quality of nursing education the students reported it was not available. This finding might be due to the teachers more oriented with policies implemented than students. and also due to lack of policies related scope of practice in each course.

This findings was in line with Pauly, et al., (2009), reported that education in the area of policy development is limited in academic programs, and the importance of nurse leaders as role models for students should be emphasized. Also Primomo, (2007), showed that the academic preparation has been suggested as a mechanism to assist nurses in valuing and identifying political involvement. While Leavitt, (2009), reported that it is a challenge for nurse educators to teach students how to translate policy, because limited time in clinical experiences prevents immersion experiences in policy development. Nursing role models, preceptors, and leaders are needed to advance learning in the area of policy development skills for all professional nurses. In relation to guidance and counseling as a factor that affecting quality of nursing education. The teachers reported it was available and very essential. This finding might be due to the teacher believe that the counselors role help the students in achieving in their a cadmic performance as well as develop their personality also might be due to not all the organizations interested to enhance to continue professional development.

In the same line Katherine, (2006), found that surveyed teachers expressed a desire to have counselors help students mostly in the personal/social domain. While the academic and career domains were both mentioned, the perceived concerns seemed to be less emphasized in these areas. Also the results of the study showed that the school counseling profession, although sometimes scrutinized, has teachers that are in support of it. In order for this support to continue, school counselors need to be continually active in keeping their colleagues educated about their role and they also need to act as advocates for themselves and for their profession

Regarding to opportunity of self-development as a factor that affecting quality of nursing education the students reported it was not available. This finding might be due to teachers staff have opportunity of self - development and join many training program more than students who had limited chance.

These finding were consistent with Hynes et al., (2012), showed that development programs play a major role in helping faculty members cultivate their roles, improved student success and student retention as well as having a positive impact on student learning, satisfaction, and motivation. While Gallagher \& Trawer (2010), reported that participation in a faculty development program can influence how faculty feel about their role as a teacher and can increase teacher self-efficacy.

\section{Conclusion}

The study was to determine the factors affect quality of nursing education in nursing technical institute at Assuit city. the findings of the study showed that there were statistically significant difference between the University nursing students \& Ministry of health students for the all main factors affecting quality of nursing education except the clinical infrastructure. In conclusion, the results of the present study displays that the incidental teaching as the most factor affecting quality of nursing education was not available, followed by new technology, nurse patient 
ratio and teacher student ratio, evaluation system, institutional policies, guidance and counseling, opportunity of self-development, clinical infrastructure, and physical facilities.

\section{Recommendations}

Consequently Based Upon Such Results, Following Recommendations are Proposed

- Asking the authorities body who responsible for the development of institutes, especially institutes affiliated to the Ministry of Health, to pay attention to the infrastructure and supply the institutes with the new buildings.

- Asking the teachers to use the incidental teaching as a method of clinical teaching.

- Increase number of clinical teachers in clinical setting to facilitate students learning.

- Apply in the beginning of course one-week orientation to clarify for the students all relevant policies related to scope of practice in that course.

- Asking the teachers to use new teaching strategies to improve critical thinking and evidence based practice.

- Pre-admission tests should be included: (tests of reading, mathematics, science, English \& psychological tests) to assess necessary traits and skills which needed to be a successful and caring nurse.

- Curriculum Development should be ongoing process especial in the institutes of Ministry of health.

- Asking to use OSCE as a method of evaluation in technical institutes.

\section{References}

1. Benner, P., (2010): transformation ,crisis and opportunity education of nurses , a call for radical transformation ,first edition, published by Jossey Bass

2. Bhushan J., (2013): Quality nursing education every one's concern , Published on Sep29,2013,NursJIndia. 2014Jan-

Feb;105(1):44-6.

http://www.williscommission.org.uk

3. Bray, L., Flynn, A., \& Sanders, C., (2011): The experiences of children's nursing students: learning urethral catheterization. Nurse Education in Practice,11, (3) 168-172.

4. Gallagher, A., \& Trower C., (2010): Trekking toward tenure: What pre-tenure faculty want on the journey. Metropolitan Universities, 21(2), 1633.

5. Graham, I., \& Richardson, E., (2008): Experiential gaming to facilitate cultural awareness: Its implication for developing emotional caring in nursing, Learning in Health and Social Care, vol. 7, no. 1, pp. 37-45.

6. Farag M., (2008): Economic analysis of the nurse shortage in Egypt. Available at: http://www.dsg.ae/ , Accessed July 25, 2011.

7. Harrison, H., (2010): Meaning of Nursing Education. USA: Jones \& Bartlett co. http//www.onsbag.com/qview2029033

8. Hynes, P., Perez, A., \&, McShannon, J., (2012): Community college faculty development program and student achievement. Community College Journal of Research and Practice, 36(5), 379-385.

9. Katherine E., (2006): Teacher perception of the role of a school counselor, University of Wisconsin-Stout. American Psychological Association, 5th edition

10. Leavitt, J., (2009): Leaders in health policy: A critical role for nursing. Nursing Outlook, 57, 7377.

11. Melone, S., (2010): Basic Nursing skills and concepts. Nursing times T.M Magazine. www.nursingtimes.net.

12. National League for Nursing (NLN) (2009): Transforming clinical nursing education. Retrieved. March 6, 2009.From: http://www.nln.org

13. Pauly, B., MacKinnon, K., \& Varcoe, C., (2009): Revisiting who gets care? Health equity as an arena for nursing action. Advances in Nursing Science, 32(2), 118-127.

14. Primomo, J., (2007): Changes in political astuteness after a health systems and policy course. Nurse Educator 32(6), 260-264.

15. Searle, C., (2000): Professional Practice: a South African Nursing Perspective.4th edn., Heinemann, Sandton.

16. Starck, P., (2005): The cost of doing business in nursing education. Journal of Professional Nursing 21(3):183-190.

17.Sumari- Ayo, E., (2006): Factors influencing clinical teaching of midwifery students in a selected clinical setting in Tanzania, University of South Africa.

18. Wanda B., (2010): The use of peer review in Nursing Education and Clinical Practice, Journal for Nursing in staff development ,Volume 26, Number 3, 108-115 Lippincott Williams \& Wilkins

19. Willis Commission. (2012): Quality with compassion the future of nursing education. Retrieved May 5, 2012. 